Available online at http://journal.ugm.ac.id/ifnp DOI: http://doi.org/10.22146/ifnp.31010
INDONESIAN FOOD AND NUTRITION PROCRESS

\title{
Sensory Evaluation of Yogurt-like Set and Yogurt-like Drink Produced by Indigenous Probiotic Strains for Market Test
}

\author{
Fathyah Hanum Pamungkaningtyas ${ }^{1)}$, Mariyatun ${ }^{1)}$, Rafli Zulfa Kamil ${ }^{1)}$, Ryan Haryo Setyawan ${ }^{1)}$, \\ Pratama Nur Hasan ${ }^{1)}$, Devin Varian Wiryohanjoyo ${ }^{1)}$, Sri Nurfiani ${ }^{2)}$, Eni Zulaichah ${ }^{21}$, Indyah S. \\ Utami $^{1)}$, Tyas Utami ${ }^{1}$, Endang S. Rahayu ${ }^{1)^{*}}$ \\ 1) Department of Food and Agricultural Product Technology, Faculty of Agricultural Technology, Universitas \\ Gadjah Mada, Flora 1, Bulaksumur, Yogyakarta, Indonesia \\ 2) PT. Yummy Food Utama, Jl. Raya Bogor No.40, Jakarta, Indonesia \\ *Corresponding author's email: endangsrahayu@ugm.ac.id
}

Received 4 December 2017; Accepted 9 April 2018; Published Online 30 May 2018

\begin{abstract}
Lactic acid bacteria have been isolated from several Indonesian indigenous fermented foods and screened for the potential strains as probiotic candidates. The aim of this study was to evaluate sensory properties and respondents' preference of yogurt-like set and yogurt-like drink with various Indonesian indigenous probiotic strains produced by dairy industry. Indigenous probiotics of Lactobacillus plantarum MUT-7 and Lactobacillus plantarum DAD-13 were used to produce yogurt-like set and yogurt-like drink. Family perception toward yogurt-like drink was performed in Yogyakarta involving 100 family members. The yogurt-like products were also compared to yogurt containing commercial Lactobacilus bulgaricus and Streptococus thermophilus or commercial yogurt produced by dairy company. Several sensory evaluation toward sensory properties and panelist's preference were performed in different cities. The result showed that the indigenous probiotic $L$. plantarum DAD-13 and L. plantarum MUT-7 were potential to be used as a starter culture for the production of yogurt-like set and yogurt-like drink. The combination of indigenous probiotics and indigenous lactic acid bacteria $S$. thermophilus DAD-11 resulted in better sensory properties of yogurt set compared to combination of L. bulgaricus and S. thermophilus.
\end{abstract}

Keywords: Indigenous probiotic; Lactobacillus plantarum; Streptococcus thermophilus; sensory evaluation; market test.

Introduction

In recent years, functional food has attracted both researchers and industries as consumers become more conscious of the health effect as the additional value to the nutrition of the food. Functional food is defined as foods and/or food components that when it is consumed, it provides a health benefit beyond basic nutrition (IFT Expert Report, -). Addition of probiotics into fermented food, particularly dairy products, is considered as functional food as several studies showed health effect of consuming probiotics. Yogurt has been known as a common source of probiotics, made from milk fermented using Staphylococcus bulgaricus and Lactobacillus bulgaricus. Yogurt-like products refer to milk which is fermented using other lactic acid bacteria. 
Probiotics by definition are living microorganisms, which, when administered in adequate amount as a dietary addition confer a health benefit on the host (FAO/ WHO, 2001, FAO/WHO, 2002). The health benefits of consuming probiotics are mainly due to the ability of the probiotics to support the balance of microbiota in intestine. The potential benefit of probiotics on physical health has been studied widely, thus probiotics are utilized by many industries as a starter culture for fermentation of dairy products. However, many industries still rely on import probiotics strains and at the moment, there is no indigenous probiotic strains have been used for food production in industry-scale to be sold in Indonesian market. On the other side, research related to screening, identification, and exploration on the benefit of indigenous probiotic candidates are increasing.

Isolation of indigenous lactic acid bacteria from various fermented foods and other sources has been done by Indonesian researchers (Antara et al., 2009; Lawalata et al., 2011; Pramono et al., 2008; Rahayu, 2003; Suhartatik et al., 2014). The lactic acid bacteria have been screened for their health benefits, such as probiotics (Rahayu, 2003; Rahayu et al., 2015); $\beta$-glucosidase producers (Suhartatik et al., 2014; Djaafar et al., 2013a); ACE inhibitor producer (Wikandari et al., 2012); isoflavone and antioxidant properties (Djaafar et al., 2013b). One of the indigenous lactic acid bacteria isolated from dadih fermented buffalo's milk - named Lactobacillus plantarum DAD-13 has been studied for its potency as a probiotic strain (Rahayu et al., 2015). The study showed that L. plantarum DAD-13 could prevent the growth of pathogenic E. coli which causes diarrhea, such as $E$. coli enterotoxigenic with the stable and unstable toxin, and $E$. coli enteropathogenic OK 111 . The administration of L. plantarum DAD-13 into Wistar rats also affect the microbiota in their fecal sample
(Sumaryati et al., 2009). Rahayu et al. (2016), reported that $L$. plantarum DAD-13 was able to survive and colonize the gastrointestinal tracts of healthy Indonesian volunteers.

Developing indigenous probiotics as a starter for fermentation of dairy product is quite challenging. In order to be accepted by the consumers, sensory properties of the product play an important role. The aim of this study is to evaluate the sensory properties of the yogurt-like drink and yogurtset like produced by indigenous probiotics for market test.

\section{Materials and Methods Sample Preparation}

This research used methanol, ethyl acetate, Folin Ciocalteu reagent, gallic acid, tannic acid (Sigma Chemical Co. St. Louis USA) $(+)$-catechine, rutin, quercetin (Waco Pure Chemical Industry-Osaka Japan), butylated hydroxyanisole/BHA (Sigma Chemical Co.), aqueous $\mathrm{Na}_{2} \mathrm{CO}_{3}$, Tween-40, $\mathrm{HCl}$, buffer phosphate $\mathrm{pH} 7$, ferrous chloride $\left(\mathrm{FeCl}_{2}\right)$, ferric chloride $\left(\mathrm{FeCl}_{3}\right)$, ammonium thiocyanate, $\mathrm{K}_{3} \mathrm{Fe}(\mathrm{CN})_{6}$, trichloroacetic acid (TCA), tungstophosphoric acid,1,1-diphenyl-2-picryl hydroxyl radical (DPPH) and linoleic fatty acid, all in analytical grade. It also used rotary vacuum evaporator (IKA-RV 10 basic), vortex, incubator, water-bath shaker (Julabo SW 22), a UV-Visible spectrophotometer (UV-1601 Shimadzu) and HPLC-DAD Hitachi Auto sampler L-2200 (Berkshire, UK).

\section{Plant Authentication and Extracts Preparation \\ Maintenance of Culture}

Probiotic strains used in this study were Lactobacillus plantarum DAD-13 which was isolated from dadih - traditional fermented buffalo milk and Lactobacillus plantarum MUT-7 which was isolated from gatot - traditional fermented raw cassava. The additional strains used were 
Streptococcus thermophilus DAD-11, commercial yogurt starter Streptococcus thermophilus and Lactobacillus bulgaricus obtained from Food and Nutrition Culture Center Collection (FNCC), Center for Food and Nutrition Studies, Universitas Gadjah Mada, Yogyakarta, Indonesia. The strains were preserved in ampoules and kept at Food and Nutrition Culture Center Collection (FNCC), Center for Food and Nutrition Studies, Universitas Gadjah Mada, Yogyakarta, Indonesia. The strain was grown in MRS (de Man, Ragosa, Sharpe) media at $30^{\circ} \mathrm{C}$ for 24 hours before used.

\section{Preparation of Starter Culture}

Starter culture was made using 300 $\mathrm{mL}$ of coconut water as a media with the addition of $250 \mathrm{~mL}$ of peptone, $400 \mathrm{~mL}$ of bean sprout extract, $20 \mathrm{~mL}$ of tomato extract, 30 grams of sucrose and $30 \mathrm{~mL}$ of distilled water. Media were homogenized and sterilized at $121^{\circ} \mathrm{C}$ for 15 minutes. The amount of $50 \mathrm{~mL}$ of each indigenous probiotic strain was inoculated into the media (10\% sterilized skim milk). While the commercial yogurt starter used was obtained from PT. Yummy Food Utama.

\section{Production of Yogurt-like Products}

The production of yogurt-like products was carried out in PT. Yummy Food Utama in Jakarta. Two kinds of products used for this study were in form of yogurt-like set and yogurt-like drink. The number of indigenous probiotics added was $3.7 \times 10^{10}$ $\mathrm{CFU} / \mathrm{mL}$. The milk was fermented and then mixed with sugar and fruit flavoring compound. Yogurt-like drink was packaged in $180 \mathrm{~mL}$ plastic bottle, while yogurt-like set was packaged in $250 \mathrm{~mL}$ plastic cup. Commercial yogurt-set used as control was yogurt-set produced by PT. Yummy Food Utama.

\section{Sensory Evaluation}

In order to ensure that the quality of food is appealing and appetising or more specifically that the eating quality attributes of aroma, taste, aftertaste, tactual properties and appearance is acceptable, method of deciding said quality of a food is through sensory evaluation (Singh-Ackbarali and Maharaj, 2014). The responses to these attributes can be used to know the preference of the consumers on yogurt products made of indigenous strain and commercial starter. The sensory evaluation was divided into four tests. The first evaluation was home-use test using families, the second was central location test held in Faculty of Agricultural Technology Universitas Gadjah Mada, whereas third and fourth evaluation were central location test held in seminar auditorium.

Home-use test was done in order to obtain responses from families which were considered the potential consumers for yogurt products. Home-use test was chosen because in home-use test, the opinion of the whole family members and their influence toward each other are taken into account (Meilgaard et al., 1999). Therefore, it is expected that the responses from home-use test can represent an even broader range of consumers.

Central location tests are usually conducted in an area where many potential purchasers congregate or can be assembled (Meilgaard et al., 1999). In this research, faculty area and seminar auditorium were chosen because there were many potential consumers for yogurt products in those places.

The first evaluation was the family perception of yogurt-like drink conducted in Yogyakarta involving 100 family members. The amount of eight bottles of yogurt-like drink (four of peach flavor and four of strawberry flavor) and questionnaires were given to each family members. Sensory 
attributes such as creaminess, sweetness, viscosity, and sourness were measured.

The second sensory evaluation involving 53 students in Yogyakarta was intended to evaluate the sensory properties of yogurt-like set products using different mixtures of strains, which were a combination of L. plantarum MUT-7 and S. thermophilus DAD-11; and combination of L. plantarum DAD-13 and $S$. thermophilus DAD-11. Commercial yogurt from PT. Yummy was used as the control.

For the third sensory evaluation, 119 university members (consist of students and staffs) of Universitas Gadjah Mada, Yogyakarta were also recruited as the panelist to evaluate the sensory properties of yogurtlike drink containing L. plantarum MUT-7 and S. thermophilus DAD-11. Commercial yogurt from PT. Yummy was used as the control.

The final sensory evaluation was performed using 101 students from Universitas Gadjah Mada in Yogyakarta and 91 students from Universitas Katholik Widya Mandala in Surabaya as the panelists to compare the sensory properties of yogurt-like set containing a combination of $L$. plantarum DAD-13 and $S$. thermophilus DAD-11 with commercial yogurt set.

\section{Results and Discussion}

Family Perception Towards Yogurt-like Drink Containing Indigenous Probiotics

The family perception evaluation was performed in Yogyakarta. Initially, a total of 48 housewives were recruited to bring a total of eight bottles of products (ratio between peach and strawberry flavored product was $1: 1)$ to be given to their family members. Each family member had to consume two yogurtlike drinks (one strawberry flavored and one peach flavored). The family member was asked to answer the questionnaire given by the researchers. The total of family members participated in this sensory evaluation was 100 persons.

Sensory attributes i.e. sweetness, sourness, viscosity, and creaminess of two different flavors of yogurt-like drink were measured. The scale ranged from 1 (the weakest sensation) to 5 (the strongest sensation). The affective evaluation was also performed in the scale of 1 (the most unfavored) to 5 (the most favored) in order to evaluate consumer's preference. The panelists were also asked for their socialeconomy backgrounds such as their latest education, amount of income, and their eating habits.

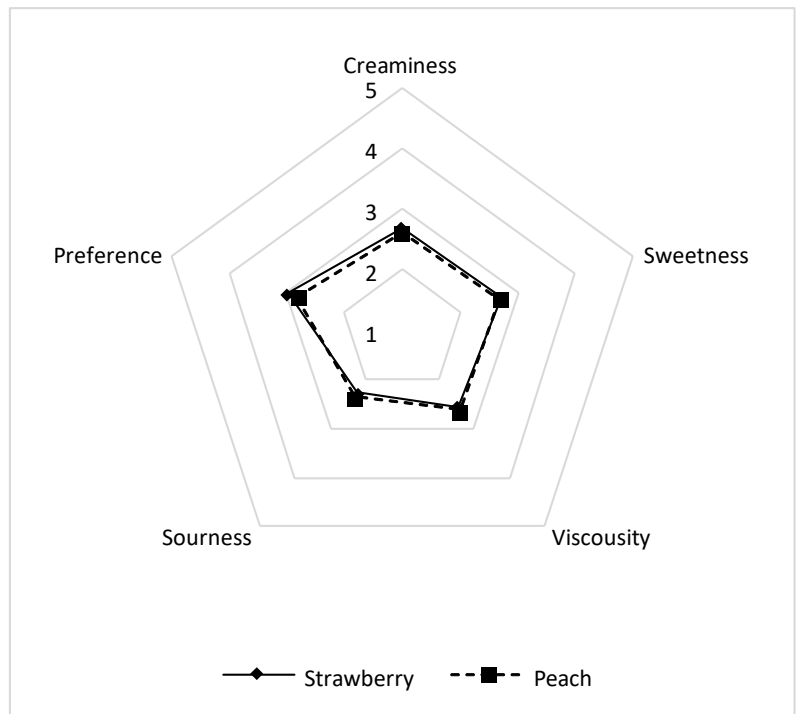

Figure 1. Family perception towards yogurt-like drink containing indigenous probiotics with different flavors. 
The result (Figure 1) showed that there was no significant difference in sensory properties between peach-flavored yogurtlike drink and strawberry-flavored yogurt-like drink. The overall perception of panelist towards both products was around the score of 3, which showed neutral position. This might be resulted by the eating habits of the panelists and might also be affected by their income. Daily consumption of fermented milk and regular buying of such products were not their priority of household needs, therefore their responses were inclined towards neutral due to the unfamiliarity and lack of previous experiences in consuming such products.

\section{Comparison of Sensory Properties of Yogurt- like Set Using Two Different Indigenous Probiotics}

Sensory attributes (creaminess/ mouthfeel, sweetness, consistency, sourness, and lingering aftertaste) and panelists' preference of yogurt-like set containing indigenous probiotics of $L$. plantarum DAD-13 combining with lactic acid bacteria $S$. thermophilus DAD-11 were measured and compared to those of yogurt-like set containing combination of indigenous probiotics L. plantarum MUT-7 and lactic acid bacteria $S$. thermophilus DAD-11. The two products were also compared to the control using the same parameters. The control was commercial yogurt-like set from PT. Yummy. The scale ranged from 1 (the weakest sensation) to 5 (the strongest sensation). The affective evaluation was also performed in the scale of 1 (the most unfavored) to 5 (the most favored) in order to evaluate consumer's preference. A total of 53 students were recruited as panelist.

Sensory evaluation of yogurt-like set products is shown in Table 1 and illustrated in Figure 2. The result showed that there is no significant difference $(p>0,05)$ in all sensory attributes between the two yogurt-like set products. Compared to the control, only sweetness attribute showed significantly different result as yogurt-like set products were sweeter than the control. This may be caused by the characteristics of indigenous probiotics (MUT-7 and DAD-13), which have slower growth rate compared to commercial bacteria, therefore resulted in higher complex sugar substrate left in the yogurt-like set compared to in commercial product. However, further research is needed for this matter.

Based on panelist's preference, it is clearly shown that the panelists preferred to consume yogurt-like set products which were made from milk fermented using indigenous probiotics. This result further emphasizes the potential of indigenous probiotics to be applied for the production of yogurt-like set.

Table 1. Comparison of sensory properties of yogurt-like set using two different indigenous probiotics.

\begin{tabular}{llcc}
\hline & $\begin{array}{c}\text { L. plantarum DAD-13 \& S. } \\
\text { thermophilus DAD-11 }\end{array}$ & $\begin{array}{c}\text { L. plantarum MUT-7 \& S. } \\
\text { thermophilus DAD-11 }\end{array}$ & $\begin{array}{c}\text { Control (L. bulgaricus \& } \\
\text { S. thermophilus) }\end{array}$ \\
\hline Mouthfeel/Creaminess & $3.08^{\mathrm{a}}$ & $3.11^{\mathrm{a}}$ & $2.85^{\mathrm{a}}$ \\
Sweetness & $2.26^{\mathrm{b}}$ & $2.38^{\mathrm{b}}$ & 1.81 \\
Consistency & $2.55^{\mathrm{c}}$ & $2.75^{\mathrm{cg}}$ & $2.94^{\mathrm{g}}$ \\
Sourness & $2.57^{\mathrm{d}}$ & $2.57^{\mathrm{d}}$ & $2.23^{\mathrm{d}}$ \\
Lingering Aftertaste & $2.72^{\mathrm{e}}$ & $2.62^{\mathrm{e}}$ & $2.75^{\mathrm{e}}$ \\
Preference & $2.53^{\mathrm{f}}$ & $2.70^{\mathrm{f}}$ & 2.19 \\
\hline
\end{tabular}

Note: The number which is followed by the same alphabet on the same row showed no significant difference based on t-test analysis with $\alpha=0.05$. 


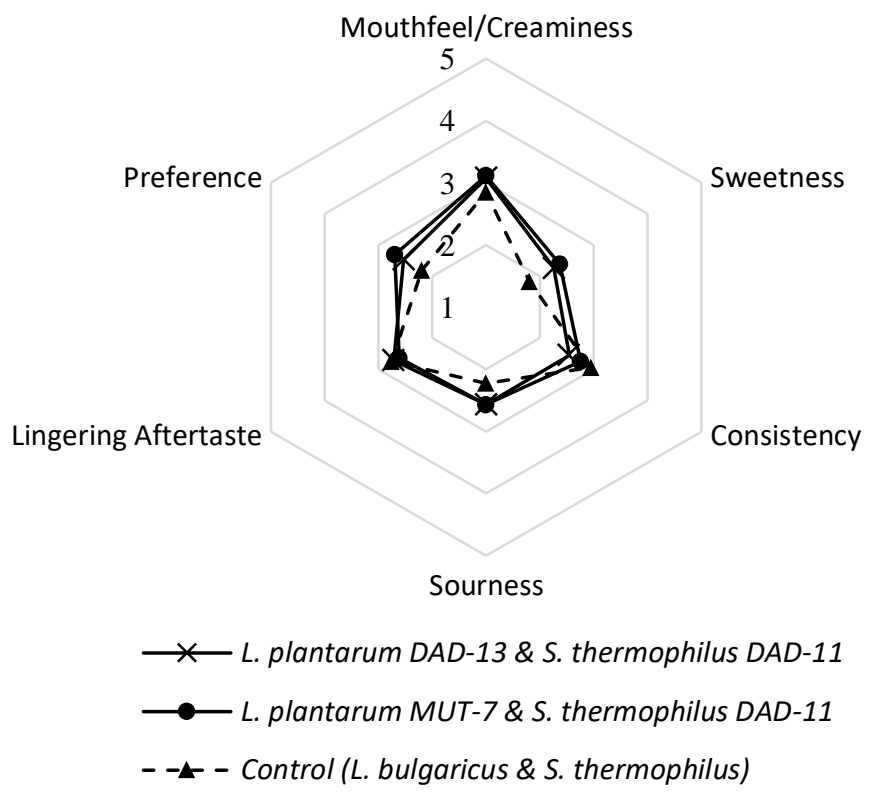

Figure 2. Sensory properties evaluation of yogurt-like set products using different mixtures of strains, which were combination of L. plantarum MUT-7 and S. thermophilus DAD-11; and combination of L. plantarum DAD13 and S.thermophilus DAD-11. A yogurt made from milk fermented using commercial yogurt starter $(S$. thermophilus and L. bulgaricus) was used as the control.

\section{Sensory Properties of Yogurt-like Drink Containing Indigenous Probiotics}

Sensory properties (creaminess/mouthfeel, sweetness, consistency, sourness, and lingering aftertaste) and panelists' preference of yogurt-like drink containing indigenous probiotics of L. plantarum MUT-7 combined with lactic acid bacteria $S$. thermophilus DAD11 were measured and compared to those of control. The control was commercial yogurt drink from PT. Yummy. The scale ranged from 1 (the weakest) to 5 (the strongest). The Affective evaluation was also performed in the scale of 1 (the most unfavored) to 5 (the most desired) in order to evaluate consumer's preference. A total of 119 students were recruited as the panelist.

Sensory evaluation of yogurt-like drink containing indigenous probiotics is shown in Table 2 and illustrated in Figure 3. The result showed that there was a significant difference in creaminess or mouthfeel, sweetness, and sourness attributes $(p<0,05)$. It is shown that yogurt-like drink was creamier, more sour, and sweeter than the control. On the other hand, attributes of consistency and lingering aftertaste between two products showed no significant difference ( $p$-value 0.32 and 0.54 , respectively). Interestingly, based on affective preference evaluation, panelist slightly preferred the yogurt-like drink with indigenous probiotics better than control even though it was not significantly different $(p<0.05)$.

\section{Comparison of Sensory Properties of Yogurt- like Set Products in Two Different Cities}

The sensory properties, i.e. aroma, mouthfeel/creaminess, sweetness, compactness, and lingering aftertaste of yogurt-like set containing L. plantarum DAD13 and $S$. thermophilus DAD-11 were evaluated and compared with those of commercial yogurt in market produced by PT. Yummy. The scale ranged from 1 (the weakest) to 5 (the strongest). The affective evaluation was also performed in the scale of 1 (the most unfavorable) to 5 (the most desired) in order to evaluate consumer's preference. Both sensory and affective 
Table 2. Sensory properties of yogurt-like drink containing indigenous probiotics

\begin{tabular}{lccc}
\hline & $\begin{array}{c}\text { Control } \\
\text { (L.bulgaricus \& S. } \\
\text { thermophilus) }\end{array}$ & $\begin{array}{c}\text { Yogurt-like drink } \\
\text { (L. plantarum MUT-7 \& S. } \\
\text { thermophilus DAD-11) }\end{array}$ & $\begin{array}{c}\text { p-value } \\
(\boldsymbol{\alpha}=\mathbf{0 , 0 5})\end{array}$ \\
\hline Mouthfeel/creamy & 2.82 & 3.13 & 0.01 \\
Sweetness & 1.87 & 2.39 & 0.00 \\
Consistency & 2.88 & 2.75 & 0.32 \\
Sourness & 2.28 & 2.76 & 0.00 \\
Lingering Aftertaste & 2.72 & 2.80 & 0.54 \\
Preference & 2.17 & 2.78 & 0.00 \\
\hline
\end{tabular}

Note: $p$-value was measured using t-test analysis with $\alpha=0.05$.

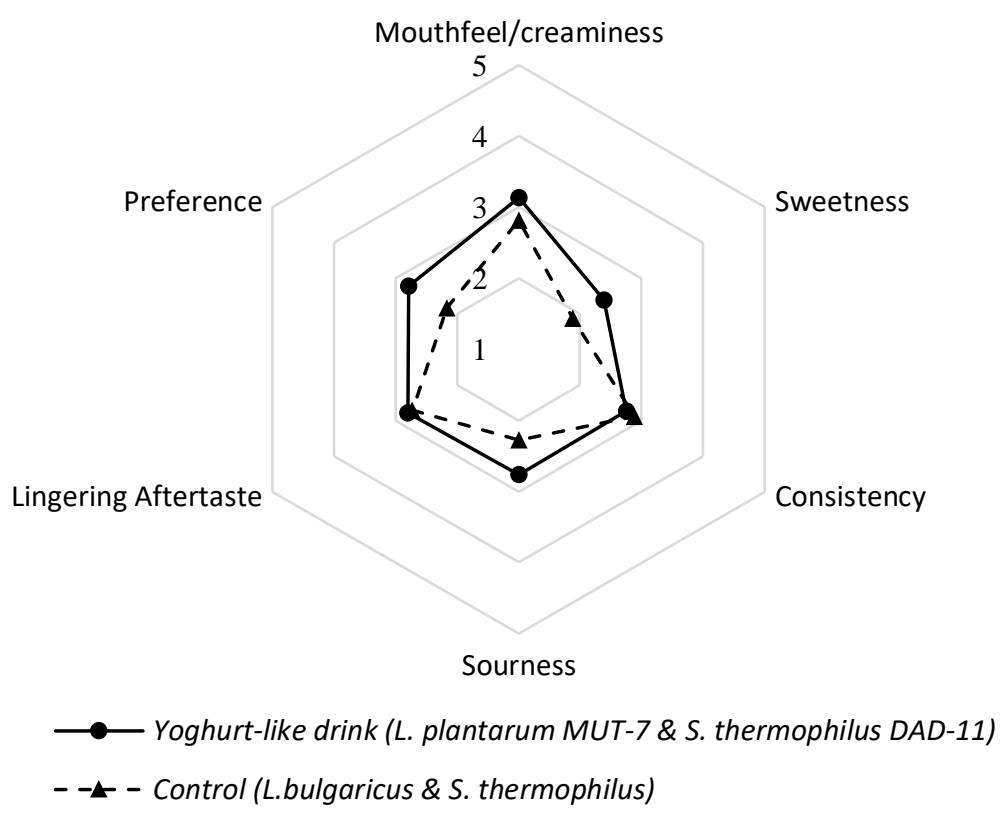

Figure 3. Sensory properties evaluation of yogurt-like drink containing L. plantarum MUT-7 and S.thermophilus DAD-11 A yogurt made from milk fermented using commercial yogurt starter (S. thermophilus and $L$. bulgaricus) was used as the control.

evaluation were performed in two different cities which were Yogyakarta (101 panelists) and Surabaya (91 panelists).

The sensory evaluation performed in Yogyakarta is shown in Table $\mathbf{3}$ and illustrated in Figure 4. Based on the evaluation done by the panelist in Yogyakarta, the aroma, mouthfeel, compactness, and lingering aftertaste of commercial yogurt were much stronger than those of yogurt-like set $(P<0,05)$. The important feature of yogurt-like set was that it had less lingering aftertaste which was favored for product such as yogurt. The sweetness and sourness of commercial yogurt were higher but not significantly different compared to those of yogurt-like set. Panelists' preference on both yogurt-like set and commercial yogurt set was not significantly different. This indicated that yogurt-like set containing indigenous probiotics was potential to be developed for market in Yogyakarta.

The sensory evaluation performed in Surabaya is shown in Table $\mathbf{4}$ and illustrated in 
Figure 5. Based on the evaluation done by the panelist in Surabaya, commercial yogurt set had significantly higher score in all of measured sensory properties. According to the affective evaluation, panelist in Surabaya preferred commercial yogurt rather than yogurt-like product with indigenous probiotics.

Table 3. Sensory evaluation of yogurt-like set using indigenous probiotics and commercial yogurt performed in Yogyakarta (101 panelist)

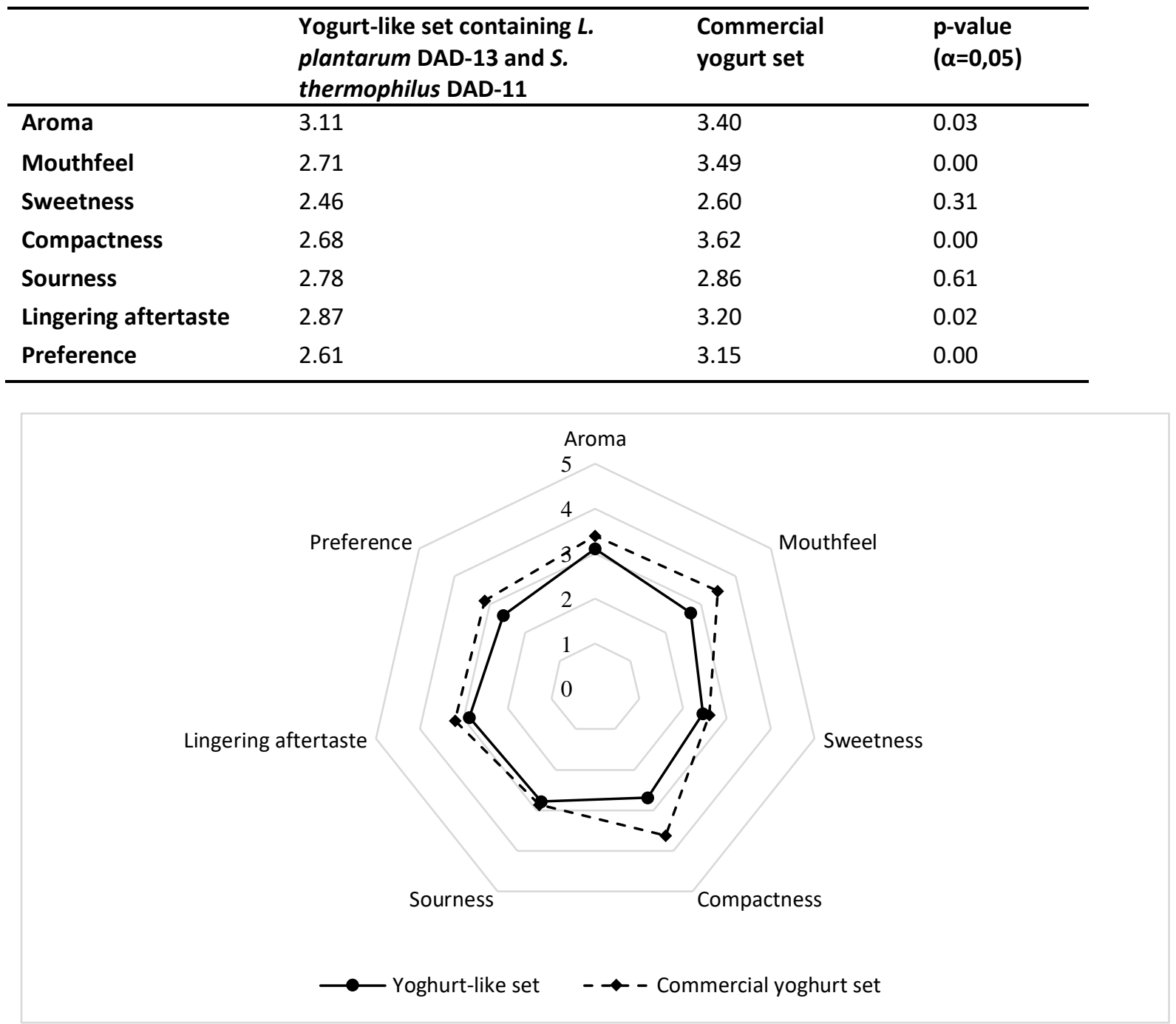

Figure 4. Comparison of sensory properties of yogurt-like set using indigenous probiotics L. plantarum DAD-13 and lactic acid bacteria $S$. thermophilus DAD-11 with commercial yogurt. Sensory evaluation was taken place using 101 students from Yogyakarta. 
Table 4. Sensory evaluation of yogurt-like set using indigenous probiotics and commercial yogurt performed in Surabaya (91 panelist)

\begin{tabular}{lccc}
\hline & $\begin{array}{c}\text { Yogurt-like set containing } L . \\
\text { plantarum DAD-13 and S. } \\
\text { thermophilus DAD-11 }\end{array}$ & $\begin{array}{c}\text { Commercial } \\
\text { yogurt set }\end{array}$ & $\begin{array}{c}\text { p-value } \\
(\boldsymbol{\alpha}=\mathbf{0 , 0 5 )}\end{array}$ \\
\hline Aroma & 3.14 & 3.55 & 0.019 \\
Mouthfeel & 2.78 & 3.25 & 0.002 \\
Sweetness & 2.03 & 2.41 & 0.015 \\
Compactness & 2.79 & 3.33 & 0.001 \\
Sourness & 2.53 & 2.95 & 0.008 \\
Lingering aftertaste & 2.47 & 2.96 & 0.003 \\
Preference & 2.18 & 2.88 & 0.000 \\
\hline
\end{tabular}

Note: $p$-value was measured using t-test analysis with $\alpha=0.05$.

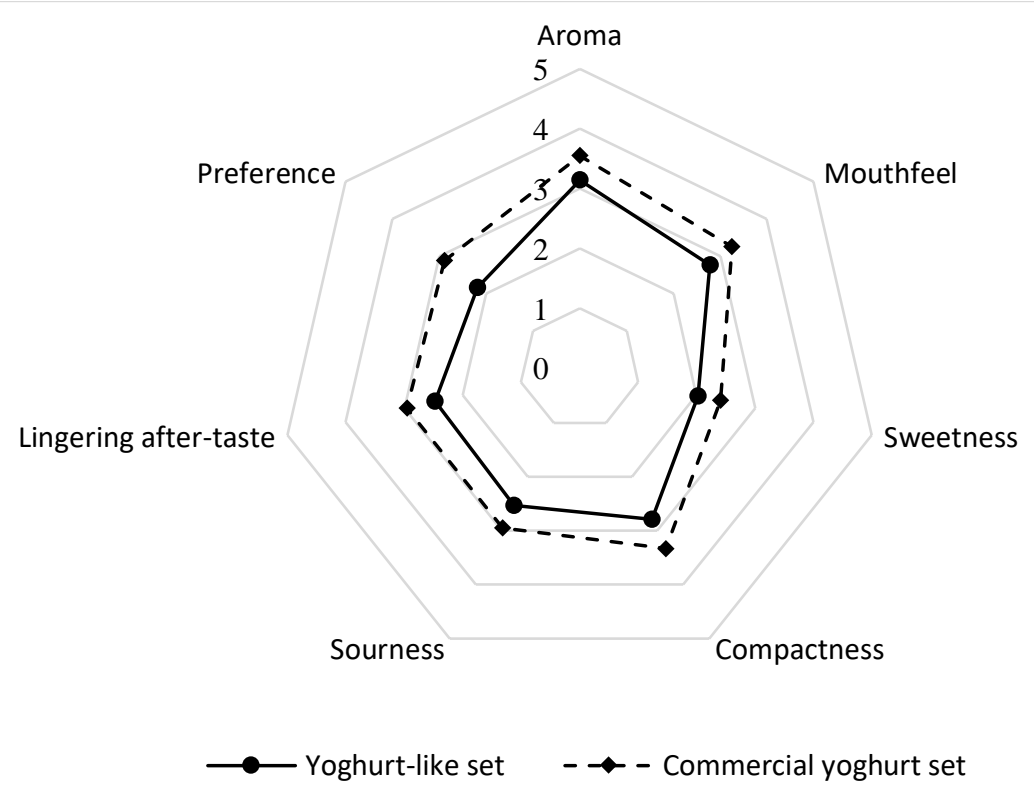

Figure 5. Comparison of sensory properties of yogurt-like set using indigenous probiotics L. plantarum DAD-13 and lactic acid bacteria $S$. thermophilus DAD-11 with commercial yogurt. Sensory evaluation was taken place using 91 students from Surabaya.

\section{Conclusion}

The indigenous probiotic $L$. plantarum DAD-13 and L. plantarum MUT-7 were potential to be used as a starter culture for the production of yogurt-like set and yogurt-like drink. The combination of indigenous probiotics and indigenous lactic acid bacteria $S$. thermophilus DAD-11 resulted in better sensory properties of yogurt set compared to combination of $L$. bulgaricus and $S$. thermophilus as shown in sensory evaluations of yogurt set in
Yogyakarta and the preferred attributes such as lower lingering taste.

\section{Acknowledgement}

The products used in this research were provided by PT. Yummy Food Utama.

\section{References}

Antara, N. S., Dibia, I. N., and Aryanta, W. R. 2009. Characteristics of lactic acid bacteria isolated from Bima mare milk (In Indonesian). Agritech 29:1-9. 
Djafaar, T. F., Cahyanto, M. N., Santoso, U., and Rahayu, E. S. (2013a). Growth of indigenous lactic acid bacteria Lactobacillus plantarum-pentosus T14 T35 in kerandang (Canavalia virosa) milk and changes of raffinose. Malaysian Journal of Microbiology 9:213-218.

Djafaar, T. F., Santoso, U., Cahyanto, M. N., Takuya, S., Rahayu, E. S., and Kosuke, N. 2013b. Effect of indigenous lactic acid bacteria fermentation on enrichment of isoflavone and antioxidant properties of kerandang (Canavalia virosa) extract. International Food Research journal 20:2945-2950.

FAO/WHO Joint Expert Consultation on Health and Nutritional Properties of Probiotics in Food Including Powder Milk with Lactic Acid Bacteria, October 2011.

FAO/WHO Joint Working Group on Drafting Guideline for the Evaluation of Probiotics in Food, April-May 2002.

IFT Expert Report, -. Functional Foods: Opportunities and Challenges. (Online) http://www.ift.org/knowledgecenter/read-ift-publications/sciencereports.

Accessed on November 20, 2017

Lawalata, H. J., Sembiring, L., and Rahayu E. S. 2011. Molecular identification of lactic acid bacteria producing antimicrobial agents from Bakasang, an Indonesian traditional fermented fish products. Indonesian Journal of Biotechnology 16:93-99.

Meilgaard, M., Civille G. V., and Carr B. T. 1999. Sensory Evaluation Techniques Third Edition. CRC Press : New York

Rahayu, E. S. 2003. Lactic acid bacteria in fermented foods of Indonesian origin. Agritech 23:75-84.

Rahayu, E.S., Yogeswara, A., Mariyatun, dkk. 2015. Molecular Characteristics of
Indigenous Probiotic Strains from Indonesia. International Jounal of Probiotic and Prebiotic 10 (4): 109-116.

Rahayu, E.S., Cahyanto M. N., Mariyatun, Sarwoko M. A., Haryono P., Windiarti L., Sutriyanto J., Kandarina I., Nurfiani S., Zulaichah E., Utami T. 2016. Effects of Consumption of Fermented Milk Containing Indigenous Probiotics Lactobacillus plantarum DAD-13 on the Fecal Microbiota of Healthy Indonesian Volunteers. International Journal of Probiotics and Prebiotics. 11(2): 91-98.

Singh-Ackbarali D., Maharaj R. 2014. Sensory Evaluation as a Tool in Determining Acceptability of Innovative Products Developed by Undergraduate Students in Food Science and Technology at The University of Trinidad and Tobago. Journal of Curriculum and Teaching. Vol. 3, No. 1; 2014

Suhartatik, N., Cahyanto, M. N., Raharjo, S., Miyashita, M., and Rahayu, E. S. 2014. Isolation and identification of lactic acid bacteria producing 3-glucosidase from Indonesian fermented foods. International Food Research Journal 21:937-942.

Sumaryati, B. T., Utami, T., and Suparmo. 2009. The effect of infection of Escherichia coli and addition of Lactobacillus plantarum DAD-13 on infected Wistar mice with Escherichia coli (In Indonesian). Agritech 29:165170.

Wikandari, P. R., Suparmo, Marsono, Y., and Rahayu, E. S. 2012. Potency of lactic acid bacteria isolated from bekasam as angiotensin converting enzyme inhibitor producer on bekasam like product fermentation (In Indonesian). Agritech 32:258-264. 